\title{
Management of Anabolic Steroid-Induced Infertility: Novel Strategies for Fertility Maintenance and Recovery
}

\author{
Alexander J. Tatem', Jonathan Beilan ${ }^{1}$ (i), Jason R. Kovac ${ }^{2}$, Larry I. Lipshultz ${ }^{1}$ (D) \\ ${ }^{1}$ Scott Department of Urology, Baylor College of Medicine, Houston, $T X,{ }^{2}$ Men's Health Center, Indianapolis, IN, USA
}

\begin{abstract}
There is often inherent conflict in the overlapping fields of male fertility and andrology. While the goal of all male fertility specialists is to facilitate and preserve biologic paternity, many practitioners also care for a significant number of patients suffering from hypogonadism. Exogenous testosterone administration, the gold standard for the management of these patients, almost universally impairs spermatogenesis and can even completely eradicate it in some men. With steady increases in both the incidence of hypogonadism and average paternal age, practitioners are now encountering hypogonadal men who desire future fertility or men suffering the effects of earlier androgenic anabolic steroid use with increasing frequency. In this manuscript, we review management strategies for these complex patients and explore novel medications that may be of use in this population.
\end{abstract}

Keywords: Anabolic steroids; Clomiphene citrate; Human chorionic gonadotropin; Hypogonadism; Infertility; Testosterone

This is an Open Access article distributed under the terms of the Creative Commons Attribution Non-Commercial License (http://creativecommons.org/licenses/by-nc/4.0) which permits unrestricted non-commercial use, distribution, and reproduction in any medium, provided the original work is properly cited.

\section{INTRODUCTION}

Physiologic functioning of the testes is essential for male fertility and male secondary sex characteristic development [1]. In men, the primary purposes of the testicles can be summarized as: 1 ) the production of testosterone and 2) spermatogenesis. These critical functions are coordinated through a complex symphony of hormonal signaling known as the hypothalamic pituitary gonadal (HPG) axis. Any dysregulation of this pathway can lead to male hypogonadism, infertility, or a combination thereof.

Male hypogonadism is a clinical entity characterized by low serum testosterone levels in conjunction with systemic symptoms that include fatigue, erectile dysfunction and mood changes [2]. It also carries known metabolic and cardiovascular risks [3,4]. Male factor infertility is defined as the inability to conceive after 12 months of unprotected intercourse. This failure to establish a pregnancy is almost always seen in conjunction with abnormal semen analysis (SA) parameters but can sometimes be present even when these values are normal $[5,6]$. Both the incidence of male hypogonadism and male factor infertility have increased markedly in recent years, making it incumbent on healthcare providers to expand their armamentarium

Received: Jan 3, 2019 Accepted: Feb 14, 2019 Published online Mar 26, 2019

Correspondence to: Larry I. Lipshultz iD https://orcid.org/0000-0001-8676-7285

Baylor College of Medicine, 6624 Fannin St, \#1700, Houston, TX 77030, USA.

Tel: +1-713-798-6270, Fax: +1-713-798-6007, E-mail: larryl@bcm.edu 
when it comes to the evaluation and treatment of these disorders [7-9].

Testosterone, the prototypical androgenic-anabolic steroid (AAS), was first isolated, characterized, and synthesized in 1935 [10,11]. Shortly after its introduction, researchers noted its ability to stimulate muscular growth and interest grew in its potential applications for supratherapeutic use and athletic performance. These effects were further popularized by the author Paul de Kruif in his 1945 book, 'The Male Hormone' [10]. Early documented uses of AAS in competitive sport include the 1952 German rowing team and the 1954 Russian weight lifting team [12]. Widespread adoption amongst Olympic athletes prompted the International Olympics Committee (IOC) to commence screening programs for AAS and their derivatives in the 1960s [13]. The use of AAS was explicitly banned starting in 1967 and in 1999 the World Anti-Doping Agency was established to help the IOC fight against illicit doping [14]. Despite this, AAS usage continues to be pervasive throughout sport and, in recent years, has increasingly been adopted by young men who are not professional athletes but simply desire to improve their physique [15].

Since the original synthesis of testosterone, several other medications have been developed that also exploit the HPG axis. Human chorionic gonadotropin (HCG), a direct luteinizing hormone (LH) analogue, has been shown to stimulate testosterone production by Leydig cells [16]. Clomiphene citrate (CC) is a wellknown centrally acting selective estrogen receptor modulator (SERM) that acts by inhibiting estrogen's negative feedback on the hypothalamus. Likely the most commonly used medication in male fertility, CC has been shown to increase serum LH, follicle stimulating hormone (FSH), and endogenous testosterone levels while preserving and even potentially improving SA parameters [17]. Tamoxifen, another SERM, possesses a similar mechanism of action [18].

\section{MECHANISMS OF ACTION}

\section{Testosterone}

Testosterone is the primary male sex hormone and original AAS. It functions by penetrating the target cell's cellular membrane and binding to an intracytosolic molecule known as the androgen receptor. This complex relocates to the nucleus where is forms a homodimer that then interfaces with an androgen response element on target genes, upregulating gene transcription and protein synthesis [19]. This results in a cascade of effects that can be seen throughout the body.

The effects of testosterone can be broadly categorized into one of two subtypes: androgenic and anabolic. The androgenic effects of testosterone include those traditionally associated with virilization, such as effects on the reproductive tract, hair growth, and sebaceous gland activity. These effects are most commonly correlated with male puberty. Testosterone's anabolic effects include increased nitrogen fixation, collagen synthesis, muscular growth, and bone metabolism with net osteoblastic activity [20].

Testosterone is synthesized by the Leydig cells of the testes as the end product of an elegant series of hormonal interactions known collectively as the HPG axis [21]. The hypothalamus, located in the forebrain, secretes gonadotropin releasing hormone in a pulsatile fashion which then travels via the hypophyseal-portal system to reach the anterior pituitary [22]. In response to this stimulus, the anterior pituitary secretes both FSH and LH. FSH acts on the Sertoli cells of the testes in order to facilitate spermatogenesis while $\mathrm{LH}$ acts on Leydig cells to stimulate testosterone production. This results in impressively high intra-testicular concentrations of testosterone that are essential for sperm production and approximately $\sim \times 40$ serum levels [16]. The remainder of testosterone is released systemically and exerts the physiologic effects detailed above.

Exogenous testosterone's deleterious effects on male reproduction stem from its disruption of the above described male HPG axis and the resulting decreases in both serum FSH and LH [23]. Without appropriate stimulation from FSH, Sertoli cells become incapable of supporting spermatogenesis while sub-par levels of $\mathrm{LH}$ lead to decreased production of endogenous testosterone from Leydig cells. Although serum testosterone levels are maintained with exogenous administration, appropriate intra-testicular levels of testosterone can only be achieved by endogenous production and are essential for normal spermatogenesis [16]. Consequently, exogenous testosterone almost universally leads to low intra-testicular testosterone with resulting atrophy of the germinal epithelium and subsequent azoospermia in upwards of $40 \%$ of men [24]. Although most men will eventually experience a return of sperm to the ejaculate following cessation of testosterone use, com- 
plete restoration of prior fertility is uncertain [25,26]. Even with adjunctive therapy, up to $30 \%$ of previously azoospermic men may fail to achieve total motile counts greater than 5 million [25].

Once released into the serum, testosterone may undergo different metabolic fates with a portion being converted into $17 \beta$-estradiol via the enzyme aromatase and another to the potent androgen dihydrotestosterone (DHT) via $5 \alpha$-reductase. A significant amount of aromatase is located within adipose tissue, leading to the increased levels of $17 \beta$-estradiol often seen in obese men $[27,28]$. This estrogen excess is associated with gynecomastia, fluid retention, sexual dysfunction, and an increased risk of thromboembolism. DHT on the other hand has a $3 \times$ affinity for the androgen receptor. Studies have shown this to be essential for normal libido and erectile function, but it also is known to contribute to undesirable androgenic side effects, such as acne, alopecia, and benign prostatic hyperplasia [29].

Normal serum levels of testosterone in the adult male range from 300 to $1,000 \mathrm{ng} / \mathrm{dL}$ with the normal physiologic production of testosterone ranging from 2.1 to $11.0 \mathrm{mg}$ per day [24]. There is an age-related decline in total serum testosterone values, resulting in an increased incidence of hypogonadism in the aging population [30]. Conversely, younger men may experience clinical symptoms of hypogonadism despite having 'normal' total serum testosterone values albeit in the lower range [31]. Testosterone levels tend to follow a natural circadian rhythm with values surging in the morning, making early morning testing essential for accurate measurement [32].

\section{Androgenic anabolic steroids}

AAS function via a mechanism of action that is almost identical to that of testosterone. Their defining features arise from their preferential anabolic effects and subsequent metabolism [33]. As a way of assessing the relative potency of AAS, Eisenberg and Gordan in 1950 proposed a novel 'myotrophic-androgenic (MA) index' that compares the relative anabolic and androgenic effects of AAS. This was done by measuring the weight of rat levator ani musculature and comparing that to seminal vesicle weight after exogenous androgen supplementation. Testosterone, as the original AAS, was assigned a MA index of 1:1 [24].

By comparison, synthetic AAS display much more favorable MA ratios. For example, the compound nan- drolone possesses a MA index of 11:1 while oxandrolone, another AAS, displays an index of 10:1 [33]. As a result, these compounds display exponentially greater myogenic potential than their parent molecule with fewer androgenic side effects. Unfortunately, like all AAS, they still disrupt the normal HPG axis in a fashion identical to exogenous testosterone.

Regarding the potential for testicular dysfunction, the threat that AAS use poses to future fertility and proper Sertoli and Leydig cell function cannot be overstated. Multiple studies have documented long-term hypogonadism stemming from prior AAS use [23,34]. One survey in particular demonstrated that the number one regret amongst prior AAS users was not understanding the potential ramifications that their AAS use may have on future fertility [35]. Many AAS users attempt to mitigate this risk by organizing their AAS usage into 'cycles' with dedicated periods of 'post-cycle therapy' that utilize medications like CC to stimulate native testicular function. Unfortunately, there have been no studies to document the efficacy of this. Although testicular failure from prior AAS use has been shown to be treatable in the vast majority of cases, success is not guaranteed and men desiring future fertility should be warned accordingly $[23,34,36]$.

Although beyond the scope of this review, the adverse effects of AAS extend far beyond the reproductive system. These are wide ranging and encompass the cardiac, hepatic, renal, musculoskeletal, endocrine and hematopoietic systems among others [33,37-40]. The challenge with studying the adverse effects of AAS is that there have been precious few clinical trials studying the consequences of these compounds in humans [41-49]. Most studies reporting adverse effects from AAS have been retrospective and anecdotal in nature with no standardization of previously used substances or dosing regimens $[39,49]$.

The study of AAS use prevalence has often been muddied by the word 'steroid' with prescribed corticosteroid use being confused with self-administered AAS usage. This has resulted with varying estimates of nonprescribed AAS usage ranging from $6.6 \%$ of male high school seniors to $7.3 \%$ of female middle schoolers [50,51]. A more rigorous review encompassing several recent studies estimates that 2.9 to 4 million Americans aged 13 to 50 have tried AAS at least once. The investigators found that the median age of first AAS use was 22 years old and that only $13.1 \%$ of users had started prior 
to age 18 . Less that $1 \%$ were estimated to be female [52].

\section{Human chorionic gonadotropin}

HCG was first identified in the blood and urine of pregnant women by Aschheim and Zondek in 1927 [53]. They hypothesized that this substance came from the anterior pituitary and demonstrated that injecting it subcutaneously in intact immature female mice produced follicular maturation, luteinization, and hemorrhage into the ovarian stroma. Later work from Seegar-Jones et al [54] showed that this substance originated not from the pituitary, but from the chorionic villi of the placenta. It was during that era that the term HCG was first used. The Dutch company Orgnanon noted its similarities in action to $\mathrm{LH}$ and first began marketing it as 'Pregnon' in 1931 [55]. Due to similarity with another trademark, its name was then changed to 'Pregnyl' in 1932 and it remains on the market to this day under this same name.

HCG use in men was subsequently studied as early as 1950 and has since been shown to effectively raise endogenous testosterone levels [56,57]. One recent study showed that hypogondal men treated with HCG monotherapy experienced an increase in their serum testosterone of approximately $\sim 250 \mathrm{ng} / \mathrm{dL}$ with an acceptable improvement of hypogondal symptoms [57]. An additional benefit of HCG is that it acts directly on the testicle, provoking a prompt response relative to indirect medications like CC that rely on pituitary synthesis of LH. It is for this reason that HCG therapy has become a cornerstone in male fertility treatment. Unfortunately, its cost, subcutaneous route of administration, and relatively short half-life (33 hours) prevent it from being used for most hypogonadal patients as primary therapy [58].

\section{Clomiphene citrate and tamoxifen}

The development of $\mathrm{CC}$ is a classic example of cooperation between industry and academia with each party offering equal contribution [59]. In 1956, while working at the William S. Merrell Chemical Company, a team led by chemist Frank P. Palopoli first developed the compound that would become known as CC. Multiple animal studies were conducted and the obvious hormonal and ovulatory effects of CC were noted [59]. It was then postulated that $\mathrm{CC}$ could assist with induction of ovulation and the first human trials were subsequently reported 1961 [60]. Shortly after this, CC use was tested in male subjects and was found to elevate both gonadotropins and SA parameters in oligospermic men [61,62]. CC has since become the most prescribed drug in the field of infertility.

Clomiphene's mechanism of action has been well described [59]. A SERM, clomiphene works by inhibiting estrogen's negative feedback loop on the hypothalamus. This stimulates gonadotropin production and accordingly promotes testicular function [17,59].

Tamoxifen, another SERM, has a similar mechanism of action [63]. Interestingly, despite being best known for its use in breast cancer, tamoxifen was initially synthesized as a potential contraceptive in 1962 in the pharmaceutical laboratories of British chemical group ICI. When it was found to actually stimulate ovulation, like clomiphene, its development was abandoned until it was co-opted for use in breast cancer in the 1980's [63]. Unlike CC, tamoxifen is quite active in the periphery which is what allows for its success in treating hormone-sensitive breast cancer. It has also proven to be an effective treatment for early onset gynecomastia in men [64]. But similar to CC, it has been demonstrated to elevate gonadotropins and improve SA parameters in sub-fertile men [65].

\section{RECOVERY OF FERTILITY AFTER PREVIOUS ANDROGENIC ANABOLIC STEROID USE}

With both the incidences of advanced paternal age and hypogonadism increasing, more and more men are presenting for fertility evaluations with histories of prior or current testosterone therapy (TTh) and AAS use [66]. In one large retrospective population study of men in the United Kingdom receiving TTh, it was estimated that $7 \%$ of me seeking assistance for infertility were receiving TTh [67]. Out of all men receiving TTh in this study, 12\% were aged 18 to 39 and in their prime reproductive years. Consequently, practitioners should familiarize themselves with maneuvers and management strategies for restoring the fertility of these patients.

Although cessation of testosterone and AAS alone has been shown to precipitate recovery of spermatogenesis, this process is often prolonged, associated with the abrupt onset of hypogonadal symptoms, and frequently a significant burden to couples. Liu et al [68] showed in a pooled analysis of 30 studies examining 
TTh as a short-term hormonal contraceptive that only $67 \%$ of previously eugonadal men will recover spermatogenesis at 6 months. For men with presumably impaired testicular function at baseline given a preexisting diagnosis of hypogonadism, it is not unreasonable to assume that their recovery would be even more prolonged. Kohn et al [25] showed that both advanced age and increased duration of TTh have negative effects on time to recovery of spermatogenesis.

Consequently, there has been increasing interest in the use of HCG to help speed these patients' recoveries. Wenker et al [69] first reported on the use of combination HCG and SERM therapy to hasten the return of sperm to the ejaculate for men with a history of TTh and AAS use in 2015. Forty-seven out of 49 men with azoospermia or severe oligospermia experienced a return of sperm to the ejaculate or significant improvement in SA parameters. Since that initial investigation, the author's proposed treatment algorithm has been refined and streamlined [18].

As a rule, all men who are actively trying for a pregnancy should immediately stop taking testosterone or AAS. This may include men taking non-prescribed AAS or men receiving TTh for an established history of hypogonadism. These men should instead start a regimen consisting of 3,000 IU HCG intramuscular or subcutaneous every other day [18]. CC 25 to $50 \mathrm{mg}$ PO (per os, by mouth) daily should also be incorporated to help promote FSH production and pituitary function [69]. During this time, repeat SA's should be obtained every 2 to 3 months along with serum labs [70]. A detailed treatment algorithm is provided in Fig. 1. Men with oligospermia should be offered cryopreservation when appropriate while men with persistent azoospermia despite treatment and no prior history of fertility or sperm on SA should have genetic studies performed to rule-out an easily diagnosable pre-existing etiology. If pregnancy is not achieved with neither FSH levels or SA parameters showing improvement, clomiphene should be discontinued and recombinant FSH 75 to 150 IU every other day should be added [18]. If this fails, testicular sperm retrieval with possible microdissection should be offered in conjunction with in-vitro fertilization as a final chance for biologic paternity. Once pregnancy has been achieved, a discussion regarding the reinitiation of TTh can be had with special consideration to future fertility goals.

\section{Steroid induced infertility}

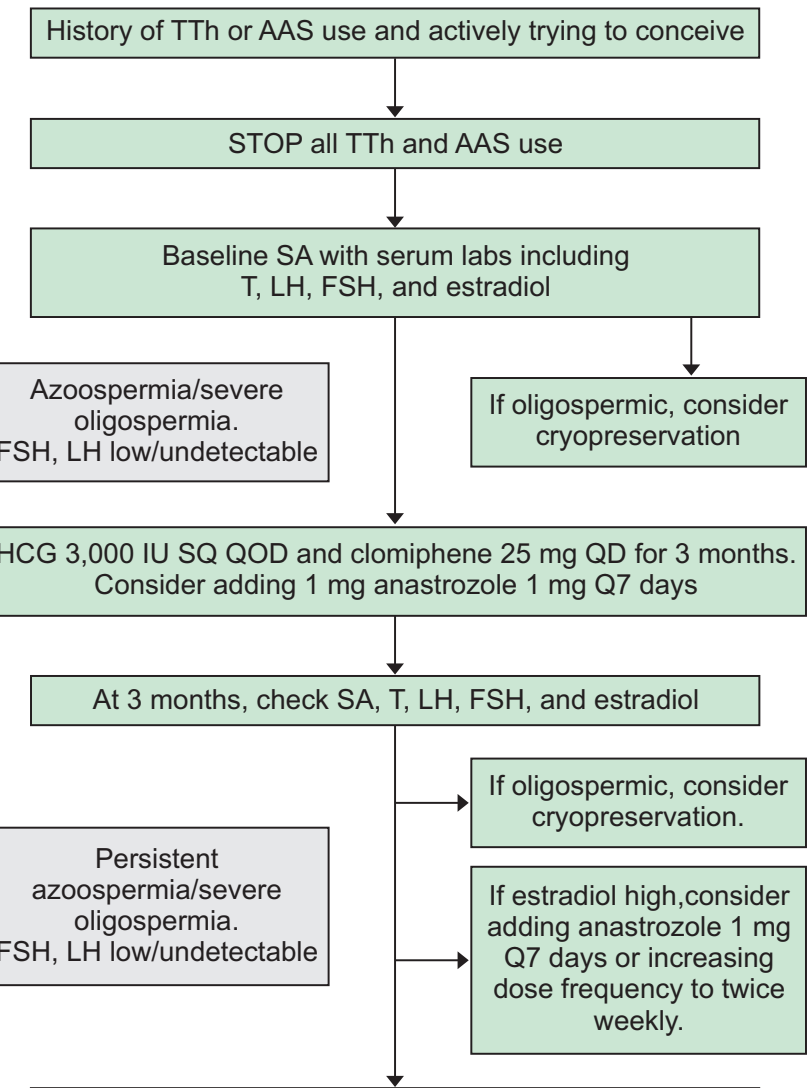

Consider obtaining karyotype or $\mathrm{Y}$ microdeletion if patient has never been involved in a pregnancy or had a previous SA with sperm.

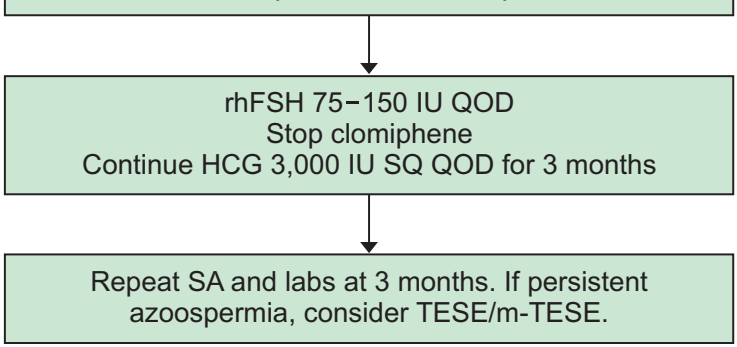

Fig. 1. Algorithm for the treatment of steroid induced infertility. TTh: testosterone therapy, AAS: androgenic-anabolic steroids, SA: semen analysis, T: testosterone, LH: luteinizing hormone, FSH: follicle stimulating hormone, HCG: human chorionic gonadotropin, SQ: subcutaneous, QOD: quaqua altera die (every other day), QD: quaque die (once a daily), Q7 days: quaque 7 days, rhFSH: recombinant human follicle stimulating hormone, TESE: testicular sperm extraction, mTESE: microdissection testicular sperm extraction.

\section{MAINTENANCE OF FERTILITY WITH CONCURRENT TESTOSTERONE USE}

Preserving testicular function and reproductive ability remains an ongoing challenge to practitioners prescribing TTh. Exogenous testosterone is known to 
decrease intratesticular testosterone and thus impair spermatogenesis. Indeed, in 1996 the World Health Organization investigated weekly injections of $200 \mathrm{mg}$ testosterone enanthate (TE) as a form of contraception. The task force demonstrated that TE caused azoospermia in approximately $75 \%$ of men after only 6 months of use [71]. Both the American Urological Association and the Endocrine Society published guidelines in 2018 which recommend against TTh in men wishing to preserve fertility [2,72]. Current evidence suggests, however, that adjuvant medications can be prescribed in an effort to maintain testicular health and fertility while receiving TTh.

Coadministration of HCG with TTh has been shown to help preserve spermatogenesis in men by maintaining physiologic intratesticular testosterone levels throughout treatment. In 2005, Coviello et al [58] demonstrated that TTh caused intratesticular testosterone levels to drop by $94 \%$ in otherwise healthy, reproductive-aged men. However, adding subcutaneous $250 \mathrm{IU}$ HCG every other day to their TTh regimen prevented this precipitous fall with intratesticular testosterone levels only dropping 7\% from baseline. Furthermore, men who received TTh and 500 IU of HCG every other day actually experienced an increase in their intratesticular testosterone by $26 \%$ [58]. This study showed that intratesticular testosterone could be reliably maintained while on TTh. Future studies would prove that spermatogenesis itself, and thus the male's fertility, could likewise be persevered throughout therapy.

A retrospective study published by Hsieh et al [73] in 2013 found that out of 26 men treated with TRT and intramuscular 500 IU HCG every other day, no patient became azoospermic. Nineteen of the 26 patients received injectable testosterone while seven were treated with transdermal testosterone gels. Mean serum hormone levels before $v s$ during treatment were: testosterone 207.2 vs. 1,055.5 ng/dL ( $<<0.0001)$, free testosterone 8.1 vs. $20.4 \mathrm{pg} / \mathrm{mL}$ ( $\mathrm{p}=0.02$ ). No differences in SA parameters were observed during greater than 1 year of follow-up. During the study's follow-up, nine men established a pregnancy with his partner [73]. This study continues to serve as the foundation of 'fertilitypreserving' TTh regimens currently utilized today.

Sensibly, all men wishing to preserve fertility while on TTh should obtain a baseline SA. During the initial consultation, it is also important to identify the patient's goals with regard to the timing of pregnancy
(Table 1). If the patient desires pregnancy within the next 6 months and has not yet started, they should abstain from initiating TTh until pregnancy has been achieved. If they desire pregnancy within 6 months and are already receiving TTh, it is recommended that they stop all TTh and follow a recovery regimen identical to what was detailed in the previous section.

If a planned pregnancy is desired within the 6 to 12 months time frame, the authors suggest continuing TTh with adjuvant 500 IU HCG every other day [18]. $\mathrm{CC}$ at a dose of $25 \mathrm{mg}$ per day should be considered an optional addition throughout this time. When planning for pregnancy over a year away, TTh with adjuvant 500 IU HCG may be continued but patients should be cycled off every six months given the increased risk of impaired fertility with prolonged, uninterrupted TTh [25]. Each off-cycle involves a four-week cycle of 3,000 IU of HCG every other day and CC $25 \mathrm{mg}$ daily. During any of these above regimens, anastrozole may be added and titrated in dose to address any elevations in estradiol. Patients who cannot tolerate CC should substitute tamoxifen $10 \mathrm{mg}$ twice daily.

Many men receiving TTh may not be interested in fertility but still wish to maintain normal testicular size. It is recommended that these individuals take 1,500 IU HCG weekly while on TTh. This dose is thought to be enough to maintain adequate levels of intratesticular testosterone in order to minimize testicular volume

Table 1. Summary of recommendations for maintenance of spermatogenesis with TTh or AAS use

\begin{tabular}{|c|c|}
\hline $\begin{array}{c}\text { Timing of desired } \\
\text { pregnancy }\end{array}$ & $\begin{array}{c}\text { Treatment } \\
\text { recommendation }\end{array}$ \\
\hline$<6$ months & $\begin{array}{l}\text { Stop TTh/AAS } \\
\text { Start 3,000 IU HCG every other day+ } \\
\text { clomiphene citrate } 25 \mathrm{mg} \text { oral daily } \\
\text { SA and labs every } 2 \text { months } \\
\text { If no FSH response, discontinue clomiphene } \\
\text { and add } 75 \text { IU rhFSH every other day }\end{array}$ \\
\hline $6-12$ months & $\begin{array}{l}\text { Continue TTh/AAS } \\
\text { Continue } 500 \text { IU HCG every other day } \pm \\
\text { clomiphene citrate } 25 \text { mg oral daily }\end{array}$ \\
\hline$>12$ months & $\begin{array}{l}\text { Continue TTh/AAS } \\
\text { Continue } 500 \text { IU HCG every other day } \\
\text { If initiating therapy, obtain a baseline SA to } \\
\text { rule out occult fertility issue. }\end{array}$ \\
\hline
\end{tabular}

TTh: testosterone therapy, AAS: androgenic-anabolic steroids, HCG: human chorionic gonadotropin, SA: semen analysis, FSH: follicle stimulating hormone, rhFSH: recombinant human follicle stimulating hormone. 
loss. Some men feel that periodically cycling off of TTh is symptomatically beneficial but this is an anecdotal observation and primarily a matter of patient preference.

\section{CONCLUSIONS}

Initiating testosterone replacement therapy requires an open and honest discussion between the physician and patient. The risks, benefits, alternatives, and expectations must be reviewed in detail with a specific focus on the reproductive implications involved with treatment. While many side effects of TTh such as cardiovascular impact remain surrounded in controversy, the findings of decreased intratesticular testosterone and subsequent impaired sperm production are welldocumented. Fortunately, the aforementioned maneuvers show promise in maintaining testicular health throughout treatment while facilitating the successful restoration of fertility when trying for pregnancy. CC and HCG both play pivotal roles in helping to restore spermatogenesis in these men. Further randomized, prospective studies are necessary to elucidate the most effective treatment programs both during and after TTh. In the meantime, men considering TTh who are interested in preserving fertility should be treated by experts familiar with the intricacies of these medical regimens.

\section{Disclosure}

The authors have no potential conflicts of interest to disclose.

\section{Author Contribution}

Conceptualization: all authors. Data curation: AJT, JB. Formal analysis: all authors. Investigation: all authors. Methodology: all authors. Project administration: AJT, JB. Resources: all authors. Software: all authors. Supervision: AJT, JB. Validation: AJT, JB. Visualization: all authors. Writing-original draft: all authors. Writing-review \& editing: all authors.

\section{REFERENCES}

1. Basaria S. Male hypogonadism. Lancet 2014;383:1250-63.

2. Mulhall JP, Trost LW, Brannigan RE, Kurtz EG, Redmon JB, Chiles KA, et al. Evaluation and management of testosterone deficiency: AUA guideline. J Urol 2018;200:423-32.
3. Kloner RA, Carson C 3rd, Dobs A, Kopecky S, Mohler ER 3rd. Testosterone and cardiovascular disease. J Am Coll Cardiol 2016;67:545-57.

4. Dimopoulou C, Goulis DG, Corona G, Maggi M. The complex association between metabolic syndrome and male hypogonadism. Metabolism 2018;86:61-8.

5. Practice Committee of the American Society for Reproductive Medicine. Diagnostic evaluation of the infertile male: a committee opinion. Fertil Steril 2015;103:e18-25.

6. Male Infertility Best Practice Policy Committee of the American Urological Association; Practice Committee of the American Society for Reproductive Medicine. Report on optimal evaluation of the infertile male. Fertil Steril 2006;86:S202-9.

7. Agarwal A, Mulgund A, Hamada A, Chyatte MR. A unique view on male infertility around the globe. Reprod Biol Endocrinol 2015;13:37.

8. McBride JA, Carson CC 3rd, Coward RM. Testosterone deficiency in the aging male. Ther Adv Urol 2016;8:47-60.

9. Mulligan T, Frick MF, Zuraw QC, Stemhagen A, McWhirter C. Prevalence of hypogonadism in males aged at least 45 years: the HIM study. Int J Clin Pract 2006;60:762-9.

10. Hoberman JM, Yesalis CE. The history of synthetic testosterone. Sci Am 1995;272:76-81.

11. Dotson JL, Brown RT. The history of the development of anabolic-androgenic steroids. Pediatr Clin North Am 2007; 54:761-9, xi.

12. Wu C, Kovac JR. Novel uses for the anabolic androgenic steroids nandrolone and oxandrolone in the management of male health. Curr Urol Rep 2016;17:72.

13. Nieschlag E, Vorona E. Mechanisms in endocrinology: medical consequences of doping with anabolic androgenic steroids: effects on reproductive functions. 2015;173:R47-58.

14. Mazzoni I, Barroso O, Rabin O. The list of prohibited substances and methods in sport: structure and review process by the world anti-doping agency. J Anal Toxicol 2011;35:60812 .

15. Kanayama G, Pope HG Jr. History and epidemiology of anabolic androgens in athletes and non-athletes. Mol Cell Endocrinol 2018;464:4-13.

16. Coviello AD, Bremner WJ, Matsumoto AM, Herbst KL, Amory JK, Anawalt BD, et al. Intratesticular testosterone concentrations comparable with serum levels are not sufficient to maintain normal sperm production in men receiving a hormonal contraceptive regimen. J Androl 2004;25:931-8.

17. Ramasamy R, Scovell JM, Kovac JR, Lipshultz LI. Testosterone supplementation versus clomiphene citrate for hypogonadism: an age matched comparison of satisfaction and efficacy. J Urol 2014;192:875-9. 
18. Ramasamy R, Armstrong JM, Lipshultz LI. Preserving fertility in the hypogonadal patient: an update. Asian J Androl 2015; 17:197-200.

19. Bs DJHMB. Androgen physiology, pharmacology and abuse. In: De Groot LJ, Beck-Peccoz P, Chrousos G, Dungan K, Grossman A, Hershman JM, et al., editors. Endotext. South Dartmouth: MDText.com, Inc.; 2000.

20. Snyder PJ, Bhasin S, Cunningham GR, Matsumoto AM, Stephens-Shields AJ, Cauley JA, et al. Lessons from the testosterone trials. Endocr Rev 2018;39:369-86.

21. Plant TM. 60 years of neuroendocrinology: the hypothalamopituitary-gonadal axis. J Endocrinol 2015;226:T41-54.

22. Tsutsumi R, Webster NJ. GnRH pulsatility, the pituitary response and reproductive dysfunction. Endocr J 2009;56:72937.

23. Rahnema CD, Lipshultz LI, Crosnoe LE, Kovac JR, Kim ED. Anabolic steroid-induced hypogonadism: diagnosis and treatment. Fertil Steril 2014;101:1271-9.

24. de Souza GL, Hallak J. Anabolic steroids and male infertility: a comprehensive review. BJU Int 2011;108:1860-5.

25. Kohn TP, Louis MR, Pickett SM, Lindgren MC, Kohn JR, Pastuszak AW, et al. Age and duration of testosterone therapy predict time to return of sperm count after human chorionic gonadotropin therapy. Fertil Steril 2017;107:351-7.e1.

26. Najari B. Azoospermia with testosterone therapy despite concomitant intramuscular human chorionic gonadotropin: NYU case of the month, July 2018. Rev Urol 2018;20:137-9.

27. Grossmann M. Hypogonadism and male obesity: focus on unresolved questions. Clin Endocrinol (Oxf) 2018;89:11-21.

28. Schneider G, Kirschner MA, Berkowitz R, Ertel NH. Increased estrogen production in obese men. J Clin Endocrinol Metab 1979;48:633-8.

29. Tóth M, Zakár T. Relative binding affinities of testosterone, 19-nortestosterone and their 5 alpha-reduced derivatives to the androgen receptor and to other androgen-binding proteins: a suggested role of 5 alpha-reductive steroid metabolism in the dissociation of "myotropic" and "androgenic" activities of 19-nortestosterone. Steroid Biochem 1982;17:653-60.

30. Wu FC, Tajar A, Pye SR, Silman AJ, Finn JD, O’Neill TW, et al. Hypothalamic-pituitary-testicular axis disruptions in older men are differentially linked to age and modifiable risk factors: the European Male Aging Study. J Clin Endocrinol Metab 2008;93:2737-45.

31. Scovell JM, Ramasamy R, Wilken N, Kovac JR, Lipshultz LI. Hypogonadal symptoms in young men are associated with a serum total testosterone threshold of $400 \mathrm{ng} / \mathrm{dL}$. BJU Int 2015;116:142-6.

32. Malik RD, Lapin B, Wang CE, Lakeman JC, Helfand BT. Are we testing appropriately for low testosterone?: characterization of tested men and compliance with current guidelines. J Sex Med 2015;12:66-75.

33. Kicman AT. Pharmacology of anabolic steroids. Br J Pharmacol 2008;154:502-21.

34. Coward RM, Rajanahally S, Kovac JR, Smith RP, Pastuszak AW, Lipshultz LI. Anabolic steroid induced hypogonadism in young men. J Urol 2013;190:2200-5.

35. Kovac JR, Scovell J, Ramasamy R, Rajanahally S, Coward RM, Smith RP, et al. Men regret anabolic steroid use due to a lack of comprehension regarding the consequences on future fertility. Andrologia 2015;47:872-8.

36. Turek PJ, Williams RH, Gilbaugh JH 3rd, Lipshultz LI. The reversibility of anabolic steroid-induced azoospermia. J Urol 1995;153:1628-30.

37. Yarrow JF, McCoy SC, Borst SE. Tissue selectivity and potential clinical applications of trenbolone (17beta-hydroxyestra4,9,11-trien-3-one): a potent anabolic steroid with reduced androgenic and estrogenic activity. Steroids 2010;75:377-89.

38. Baggish AL, Weiner RB, Kanayama G, Hudson JI, Lu MT, Hoffmann U, et al. Cardiovascular toxicity of illicit anabolicandrogenic steroid use. Circulation 2017;135:1991-2002.

39. Pope HG Jr, Wood RI, Rogol A, Nyberg F, Bowers L, Bhasin S. Adverse health consequences of performance-enhancing drugs: an Endocrine Society scientific statement. Endocr Rev 2014;35:341-75.

40. Rasmussen JJ, Selmer C, Østergren PB, Pedersen KB, Schou M, Gustafsson F, et al. Former abusers of anabolic androgenic steroids exhibit decreased testosterone levels and hypogonadal symptoms years after cessation: a case-control study. PLoS One 2016;11:e0161208.

41. Rosenfeld J, King RM, Smith JE. Oxandrolone in ALS: preliminary analysis. Amyotroph Lateral Scler Other Motor Neuron Disord 2000;1 Suppl 4:21-5; discussion 25-6.

42. Papadimitriou A, Preece MA, Rolland-Cachera MF, Stanhope R. The anabolic steroid oxandrolone increases muscle mass in prepubertal boys with constitutional delay of growth. J Pediatr Endocrinol Metab 2001;14:725-7.

43. Grunfeld C, Kotler DP, Dobs A, Glesby M, Bhasin S. Oxandrolone in the treatment of HIV-associated weight loss in men: a randomized, double-blind, placebo-controlled study. J Acquir Immune Defic Syndr 2006;41:304-14.

44. Menke LA, Sas TC, Zandwijken GR, de Ridder MA, Stijnen T, de Muinck Keizer-Schrama SM, et al. he effect of oxandrolone on body proportions and body composition in growth hormone-treated girls with Turner syndrome. Clin Endocrinol (Oxf) 2010;73:212-9.

45. Mavros Y, O’Neill E, Connerty M, Bean JF, Broe K, Kiel 
DP, et al. Oxandrolone augmentation of resistance training in older women: a randomized trial. Med Sci Sports Exerc 2015;47:2257-67.

46. Li H, Guo Y, Yang Z, Roy M, Guo Q. The efficacy and safety of oxandrolone treatment for patients with severe burns: a systematic review and meta-analysis. Burns 2016;42:717-27.

47. Burch PT, Spigarelli MG, Lambert LM, Loftus PD, Sherwin CM, Linakis MW, et al. Use of oxandrolone to promote growth in neonates following surgery for complex congenital heart disease: an open-label pilot trial. Congenit Heart Dis 2016;11:693-9.

48. Davis SM, Cox-Martin MG, Bardsley MZ, Kowal K, Zeitler PS, Ross JL. Effects of oxandrolone on cardiometabolic health in boys with Klinefelter syndrome: a randomized controlled trial. J Clin Endocrinol Metab 2017;102:176-84.

49. Vorona E, Nieschlag E. Adverse effects of doping with anabolic androgenic steroids in competitive athletics, recreational sports and bodybuilding. Minerva Endocrinol 2018;43:47688.

50. Buckley WE, Yesalis CE 3rd, Friedl KE, Anderson WA, Streit $\mathrm{AL}$, Wright JE. Estimated prevalence of anabolic steroid use among male high school seniors. JAMA 1988;260:3441-5.

51. Grunbaum JA, Kann L, Kinchen S, Ross J, Hawkins J, Lowry R, et al. Youth risk behavior surveillance: United States, 2003. MMWR Surveill Summ 2004;53:1-96.

52. Pope HG Jr, Kanayama G, Athey A, Ryan E, Hudson JI, Baggish A. The lifetime prevalence of anabolic-androgenic steroid use and dependence in Americans: current best estimates. Am J Addict 2014;23:371-7.

53. Aschheim S, Zondek B. Hypophysenvorderlappenhormon und ovarialhormon im harn von schwangeren. Klin Wochenschr 1927;6:1322.

54. Seegar-Jones GE, Gey Go, Ghisletta M. Hormone production by placental cells maintained in continuous culture. Bull Johns Hopkins Hosp 1943;72:26-38.

55. Lunenfeld B. Historical perspectives in gonadotrophin therapy. Hum Reprod Update 2004;10:453-67.

56. Landau RL, Knowlton K, Lugibihl K, Brandt M, Kenyon AT. The anabolic effects of chorionic gonadotropin in normal young men. J Clin Invest 1950;29:619-29.

57. Habous M, Giona S, Tealab A, Aziz M, Williamson B, Nassar $\mathrm{M}$, et al. Clomiphene citrate and human chorionic gonadotropin are both effective in restoring testosterone in hypogonadism: a short-course randomized study. BJU Int 2018;122:88997.

58. Coviello AD, Matsumoto AM, Bremner WJ, Herbst KL, Amory JK, Anawalt BD, et al. Low-dose human chorionic gonadotropin maintains intratesticular testosterone in normal men with testosterone-induced gonadotropin suppression. J Clin Endocrinol Metab 2005;90:2595-602.

59. Dickey RP, Holtkamp DE. Development, pharmacology and clinical experience with clomiphene citrate. Hum Reprod Update 1996;2:483-506.

60. Greenblatt RB, Barfield WE, Jungck EC, Ray AW. Induction of ovulation with MRL/41. Preliminary report. JAMA 1961; 178:101-4.

61. Jungck EC, Roy S, Greenblatt RB, Mahesh VB. Effect of clomiphene citrate on spermatogenesis in the human. A preliminary report. Fertil Steril 1964;15:40-3.

62. Mellinger RC, Thompson RJ. The effect of clomiphene citrate in male infertility. Fertil Steril 1966;17:94-103.

63. Quirke VM. Tamoxifen from failed contraceptive pill to bestselling breast cancer medicine: a case-study in pharmaceutical innovation. Front Pharmacol 2017;8:620.

64. Mannu GS, Sudul M, Bettencourt-Silva JH, Tsoti SM, Cunnick G, Ahmed SF. Role of tamoxifen in idiopathic gynecomastia: a 10-year prospective cohort study. Breast J 2018;24: 1043-5.

65. Tsourdi E, Kourtis A, Farmakiotis D, Katsikis I, Salmas M, Panidis D. The effect of selective estrogen receptor modulator administration on the hypothalamic-pituitary-testicular axis in men with idiopathic oligozoospermia. Fertil Steril 2009; 91(4 Suppl):1427-30.

66. Kovac JR, Addai J, Smith RP, Coward RM, Lamb DJ, Lipshultz LI. The effects of advanced paternal age on fertility. Asian J Androl 2013;15:723-8.

67. Layton JB, Li D, Meier CR, Sharpless JL, Stürmer T, Jick SS, et al. Testosterone lab testing and initiation in the United Kingdom and the United States, 2000 to 2011. J Clin Endocrinol Metab 2014;99:835-42.

68. Liu PY, Swerdloff RS, Christenson PD, Handelsman DJ, Wang C; Hormonal Male Contraception Summit Group. Rate, extent, and modifiers of spermatogenic recovery after hormonal male contraception: an integrated analysis. Lancet 2006;367: 1412-20.

69. Wenker EP, Dupree JM, Langille GM, Kovac J, Ramasamy R, Lamb D, et al. The use of HCG-based combination therapy for recovery of spermatogenesis after testosterone use. J Sex Med 2015;12:1334-7.

70. Lee JA, Ramasamy R. Indications for the use of human chorionic gonadotropic hormone for the management of infertility in hypogonadal men. Transl Androl Urol 2018;7:S348-52.

71. World Health Organization Task Force on Methods for the Regulation of Male Fertility. Contraceptive efficacy of testosterone-induced azoospermia and oligozoospermia in normal men. Fertil Steril 1996;65:821-9. 
72. Bhasin S, Brito JP, Cunningham GR, Hayes FJ, Hodis HN, Matsumoto AM, et al. Testosterone therapy in men with hypogonadism: an Endocrine Society clinical practice guideline. J Clin Endocrinol Metab 2018;103:1715-44.
73. Hsieh TC, Pastuszak AW, Hwang K, Lipshultz LI. Concomitant intramuscular human chorionic gonadotropin preserves spermatogenesis in men undergoing testosterone replacement therapy. J Urol 2013;189:647-50. 